\title{
Analisis Performansi Turbin dan Generator di PLTP Lahendong Unit 1 Tomohon
}

\author{
La Ode Musa ${ }^{1 *}$, Abdul Rahman ${ }^{2}$, Ikral Gapshel ${ }^{3}$, Triska Sombokanan $^{4}$ \\ ${ }^{1}$ Jurusan Teknik Mesin, Politeknik Negeri Ujung Pandang, Makassar 90245, Indonesia \\ *laode_musa@poliupg.ac.id
}

\begin{abstract}
Lahendong Geothermal power plant is one of the Geothermal power plants in Indonesia which has four units and it be able to generate $4 \times 20 \mathrm{MW}$ of electrical energy by utilizing geothermal energy in the form of steam that supplied from wells created by Pertamina. The aim of this study is to determine the performance of the turbine and generator unit 1 which has been operated since 2001 by using thermodynamic analysis method calculating the steam quality and turbine work. Afterwards, turbine efficiency, turbine power and generator power were obtained. The average quality of geothermal steam at Lahendong in 2001 and 2015 were 0.8002 and 0.8065. Turbine's performance decreased in $2001(664.021 \mathrm{~kJ} / \mathrm{kg})$ until 2015 (640.799 kJ / kg), with the highest generator rotation tolerance of $0.9 \%$.
\end{abstract}

Keywords: steam quality, performance turbine, turbine efficiency, tolerance generators, generator power, and turbine power

\begin{abstract}
Abstrak: PLTP Lahendong merupakan salah satu pembangkit Geothermal di Indonesia yang memiliki 4 unit dan mampu membangkitkan energi listrik sebesar $4 \times 20 \mathrm{MW}$ dengan memanfaatkan tenaga panas bumi berupa uap yang disuplai dari sumur-sumur yang dibuat oleh pertamina. Penelitian ini dimaksudkan untuk mengetahui performansi turbin dan generator unit 1 yang sudah beroperasi sejak tahun 2001 dengan mengunakan metode analisis termodinamika untuk menghitung kualitas uap dan kerja turbin setelah itu akan diperoleh efisiensi turbin, daya turbin dan daya generator. Kualitas uap pada PLTP Lahendong tahun 2001 rata-rata 0,8002, tahun 2015 ratarata 0,8065 dan performansi turbin mengalami penurunan dari tahun 2001 sampai tahun 2015 dengan tahun 2001 rata-rata $664,021 \mathrm{~kJ} / \mathrm{kg}$ dan tahun 2015 rata-rata $640,799 \mathrm{~kJ} / \mathrm{kg}$, dengan toleransi putaran generator tertinggi 0,9 $\%$.
\end{abstract}

Kata kunci : kualitas uap, performansi turbin; efisiensin turbin; toleransi generator, daya generator, daya turbin.

\section{PENDAHULUAN}

Indonesia adalah salah satu negara berkembang yang sedang mengalami gejolak kemajuan industri. Hal ini menyebabkan kebutuhan energi listrik bagi negara sangat besar. Untuk memenuhi kebutuhan energi tersebut, dibangun pusat-pusat pembangkit listrik yang salah satunya adalah Pembangkit listrik tenaga Panas Bumi (PLTP).

PLTP merupakan energi terbarukan dan ramah lingkungan, karena dalam proses pembentukan uap dilakukan oleh alam yang berasal dari magma di dalam perut bumi. Sehingga dalam proses konversi energi listrik tidak lagi diperlukan bahan bakar yang mahal dan tidak ramah lingkungan seperti batu bara atau bahan bakar minyak untuk menghasilkan uap. PLTP Lahendong merupakan salah satu pembangkit panas bumi yang ada di Indonesia, terletak di kota Tomohon, Kecamatan Tomohon Selatan. PLTP Lahendong sendiri mampu membangkitkan energi listrik sebesar $4 \times 20 \mathrm{MW}$.

Suatu Pembangkit Listrik Panas Bumi harus mampu menjaga performansi tetap stabil agar produksi listrik dapat mencapai kualitas yang maksimal. Namun pada kenyataanya, performansi PLTP Lahendong tidak stabil. Berdasarkan studi lapangan penurunan performansi PLTP Lahendong dipengaruhi penurunan performansi turbin dimana separator masih dalam kondisi yang baik dengan nilai cos e pada generator masih dalam keadaan baik yaitu 0,8 .

Sebelumnya telah dilakukan penilitian performansi turbin pada PLPT Kamojang, Jawa Barat [1]. Sedangkan pada penelitian ini dilakukan analisis terhadap performansi turbin khususnya di PLTP Lahendong. Untuk mengetahui bagaimana performansi turbin dan generator di PLTP Lahendong, maka dilakukan studi dengan judul Analisi Performansi Turbin dan Generator pada PLTP Lahendong unit 1 Tumohon. 


\section{A. Prinsip Kerja Pengoperasian PLTP Lahendong}

Sistem pembangkitan PLTP Lahendong merupakan sistem pembangkitan yang memanfaatkan tenaga panas bumi yang berupa uap. Uap tersebut diperoleh dari sumur-sumur produksi yang dibuat oleh Pertamina[2]. Uap dari sumur produksi mula-mula dialirkan ke steam receiving header yang berfungsi menjamin pasokan uap agar tidak mengalami gangguan meskipun terjadi perubahan pasokan dari sumur produksi. Selanjutnya melalui flow meter, uap tersebut dialirkan ke unit 1, unit 2, unit 3 dan unit 4. Uap dialirkan ke separator untuk memisahkan zat-zat padat, silica, dan bintik-bintik air yang terbawa di dalamnya. Hal ini dilakukan untuk menghindari terjadinya vibrasi, erosi dan pembentukkan kerak pada turbin. Uap yang telah melewati separator tersebut kemudian dialirkan ke demister yang berfungsi sebagai pemisah akhir. Uap yang telah bersih itu kemudian dialirkan melalui main steam valve (MSV)-governor valve menuju ke turbin. Uap berfungsi untuk memutar sudu-sudu turbin yang dikopel dengan generator pada putaran $3000 \mathrm{rpm}$. Proses ini menghasilkan energi listrik dengan arus 3 fasa, frekuensi $50 \mathrm{~Hz}$, dengan tegangan $11 \mathrm{KV}$ [3].

\section{B. Siklus Uap Kering}

Sistem konversi fluida uap kering merupakan sistem konversi yang palingsederhana dan paling murah. Uap kering langsung dialirkan menuju turbin kemudian setelah dimanfaatkan dialirkan ke kondensor (condensing turbine).

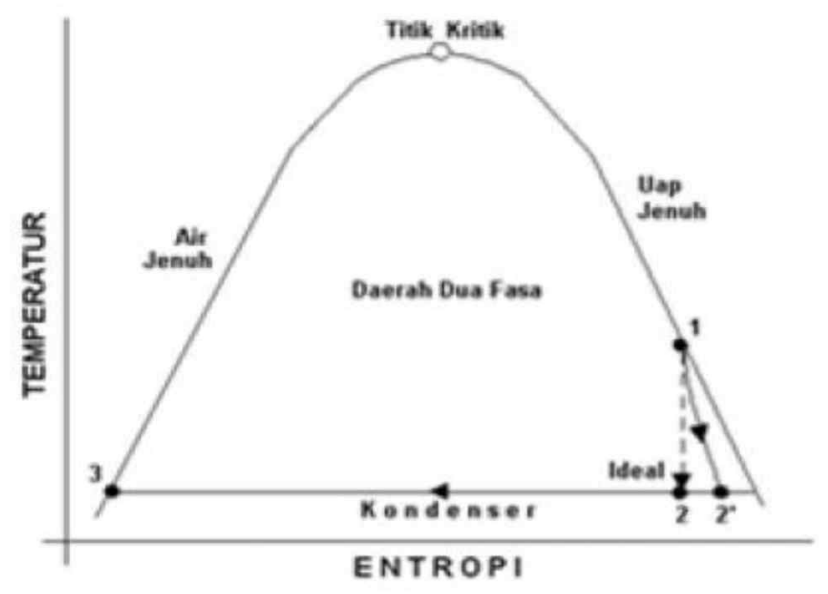

Gambar 1. Diagram T-S untuk sistem konversi uap kering [1]

Titik 1 fasa fluida panas bumi berupa uap sedangkan pada titik 2 fluida berupa dua fasa. Proses yang dijalani fluida dari titik 1 ke titik 2 dianggap proses isentropik sehingga entropi pada titik 1 sama dengan entropi pada titik 2. Laju alir masa uap yang di butuhkan untuk memasok PLTP berkapasitas P ditentukan dengan menggunakan persamaan berikut [1].

$$
\mathrm{Pt}=\dot{\mathrm{m}} \times \eta \mathrm{x}\left(\mathrm{h}_{1}-\mathrm{h}_{2}{ }^{\prime}\right) \ldots \ldots \ldots \ldots .
$$

Dimana:

$$
\begin{aligned}
& \dot{\mathrm{m}}=\text { laju alir masa uap }(\mathrm{kg} / \mathrm{s}) \\
& \mathrm{Pt}=\text { daya listrik }(\mathrm{kW}) \\
& \mathrm{\eta}=\text { effisiensi turbin }(\%) \\
& \mathrm{h}_{1}=\text { entalpi pada masukan turbin }(\mathrm{kJ} / \mathrm{kg}) \\
& \mathrm{h}_{2}=\text { entalpi pada keluaran turbin kondisi ideal }(\mathrm{kJ} / \mathrm{kg}) \\
& \mathrm{h}_{2}=\text { entalpi pada keluaran turbin kondisi aktual }(\mathrm{kJ} / \mathrm{kg})
\end{aligned}
$$

Sesuai dengan diagram T-s di atas pada proses ini terjadi proses isobarik atau tekanan konstan. Dalam proses ini dapat diketahui nilai X (kualitas fraksi kekeringan) yaitu dengan rumus [1] : 
27 La Ode Musa, Abdul Rahman, Ikral Gapshel, Triska Sombokanan. Analisis Performansi Turbin dan Generator di PLTP Lahendong Unit 1 Tomohon

$$
\mathrm{X}_{2}=\frac{s_{1-S_{2}}}{S_{2-S_{2}}} \ldots \ldots \ldots \ldots \ldots \ldots \ldots \ldots \ldots \ldots \ldots \ldots \ldots
$$

Dimana :

$\mathrm{X}_{2}=$ Kualitas Uap (\%)

$\mathrm{S}_{1}=$ Entropi uap masuk turbin $(\mathrm{kJ} / \mathrm{kg} \circ \mathrm{K})$

$\mathrm{Sg}_{2}$ dan $\mathrm{Sf}_{2}=$ Entropi uap masuk kondensor $(\mathrm{kJ} / \mathrm{kg} \circ \mathrm{K})$

Dengan diketahui nilai dari $\mathrm{X}_{2}$ (kualitas fraksi kekeringan) maka dapat dihitung nilai $\mathrm{h}_{2}$ yaitu dengan rumus [4].

$\mathrm{h}_{2},=\mathrm{hf}_{2}+\mathrm{X}_{2} \mathrm{hfg}_{2}$

Proses yang dijalani fluida dari titik 1 ke titik 2 dianggap proses isentropik sehingga entropi pada titik 1 sama dengan entropi pada titik 2 , sehingga $S_{1}=S_{2}$ dimana $S_{1}$ adalah entropi uap pada tekanan masuk turbin.

Untuk mencari effisiensi isentropik turbin digunakan rumus[1]

$\eta=\frac{W \mathrm{t}}{\text { Wt: } \mathrm{t}} \times 100 \% \ldots \ldots \ldots$

Dimana:

$\eta=$ efisiensi isentropik $(\%)$

$\mathrm{w}=$ kerja pada keadaan ideal $(\mathrm{kJ} / \mathrm{kg})$

$\mathrm{w}_{\mathrm{ts}}=$ kerja pada keadaan aktual $(\mathrm{kJ} / \mathrm{kg})$

Dari hasil diatas maka dapat dihitung kerja turbin dengan rumus:

kerja turbin dengan rumus:

$\mathrm{W}_{\mathrm{t}}=\left(\mathrm{h}_{1}-\mathrm{h}_{2}{ }^{\prime}\right) \times \eta$ isentropik turbin

Dimana:

$\mathrm{w}_{\mathrm{t}}=$ kerja turbin $(\mathrm{kJ} / \mathrm{kg})$

$\mathrm{h}_{1}=$ entalpi pada masukan turbin $(\mathrm{kJ} / \mathrm{kg})$

$\mathrm{h}_{2}{ }^{\prime}=$ entalpi keluaran turbin kondisi aktual $(\mathrm{kJ} / \mathrm{kg})$

$\eta=$ efisiensi isentropik turbin (\%)

Setelah kerja turbin diketahui maka dapat dihitung daya turbin dengan menggunakan rumus:

$\mathrm{P}_{\mathrm{t}}=\mathrm{w}_{\mathrm{t}} \mathrm{x} \dot{\mathrm{m}}$

Dimana:

$\mathrm{P}_{\mathrm{t}}=$ daya turbin $(\mathrm{kW})$

$\mathrm{W}_{\mathrm{t}}=$ kerja turbin $(\mathrm{kJ} / \mathrm{kg})$

$\dot{\mathrm{m}}=$ laju aliran massa uap $(\mathrm{kg} / \mathrm{s})$

Untuk menghitung nilai daya generator dapat dilakukan dengan menggunakan rumus:

$\mathrm{P}_{\mathrm{g}}=\mathrm{P}_{\mathrm{t}} \times \eta_{\mathrm{g}}$

Dimana:

$\mathrm{P}_{\mathrm{g}}=$ daya generator $(\mathrm{kW})$

$\mathrm{P}_{\mathrm{t}}=$ daya turbin $(\mathrm{kW})$

$\eta_{\mathrm{g}}=$ efisiensi generator $(\%)$

Sedangkan menghitung nilai toleransi putaran generator dengan menggunakan rumus:

$\mathrm{t}_{\mathrm{g}}=\frac{\Delta N}{2 N} \times 100$

Dimana:

$\mathrm{t}_{\mathrm{g}}=$ toleransi putaran generator $(\%)$

$\Delta \mathrm{N}=$ selisi antara Nmax dan Nmin (rpm)

$\mathrm{N}=$ nilai putaran acuan $(\mathrm{rpm})$

\section{Entropi}

Entropi adalah salah satu besaran termodinamika yang mengukur energi dalam sistem per satuan 
temperatur yang tak dapat digunakan untuk melakukan usaha. Entropi suatu sistem perlu diukur untuk menentukan bahwa energi tidak dapat dipakai untuk melakukan usaha pada proses-proses termodinamika. Entropi juga menunjukkan bahwa energi panas selalu mengalir secara spontan dari daerah yang suhunya lebih tinggi ke daerah yang suhunya lebih rendah [5].

\section{METODE PENELITIAN}

Penelitian ini merupakan analisis performansi turbin dan generator pada PLTP dan pengambilan data dilakukan di PT. PLN (persero) wilayah Sulutenggo Sektor pembangkit Minahasa Unit PLTP Lahendong, Jl. Esa Matuari No. 62, Tondangow, Tomohon Selatan, Sulawesi Utara, Indonesia.

\section{A. Teknik Pengumpulan Data}

Cara yang digunakan dalam pengambilan data pada penelitian ini adalah:

1. Observasi Lapangan (Field Research)

Penulis melakukan penelitian secara langsung terhadap obyek penelitian untuk memperoleh datadata yang akan diperlukan dengan turun langsung ke lapangan dan memahami sistem yang ada di PLTP Lahendong dari proses menghasilkan uap untuk kerja sistem hingga mendapatkan hasil yaitu listrik (MW)

2. Pengambilan Data

Setelah melakukan observasi lapangan, dilakukan pengambilan data sesuai yang dibutuhkan untuk bahan Tugas Akhir. Agar data - data yang diperoleh itu valid, tidak hanya mencantumkan data yang diperoleh dari operator (control room) tapi juga mencatat data pada alat mesin tersebut, sehingga diperoleh data aktual dan data dari control room.

3. Diskusi

Dilakukan setelah mendapatkan data dengan cara observasi lapangan dan wawancara secara langsung dengan karyawan PLTP Lahendong. Hal ini dimaksudkan untuk mengukur prestasi kegiatan yang telah dilakukan.

\section{B. Metode Analisis Data}

Adapun penelitian yang dilakukan adalah dengan cara pengumpulan data-data lapangan. Kemudian menghitung kualitas uap, menghitung efisiensi isentropik, menghitung kemampuan kerja turbin dan generator dan membuat grafik perbandingan dari data sekunder yang telah diperoleh.

\section{HASIL DAN PEMBAHASAN}

\section{A. Hasil}

\section{Perhitungan pada kondisi Ideal PLTP Lahendong}

Berdasarkan data heat balance diperoleh data input turbin sebagai berikut:

$\mathrm{H}_{\mathrm{s}}=2768,9 \mathrm{~kJ} / \mathrm{kg}$

$\mathrm{P}_{\mathrm{s}}=8 \mathrm{bar}$

$\mathrm{T}_{\mathrm{s}}=171^{\circ} \mathrm{C}$

$\mathrm{F}_{\mathrm{s}}=40,35 \mathrm{t} / \mathrm{h}$

$\mathrm{F}_{\mathrm{s}}=0,24 \mathrm{t} / \mathrm{h}$

Data output turbin sebagai berikut:

$\mathrm{H}_{\mathrm{s}}=2257,5 \mathrm{~kJ} / \mathrm{kg}$

$\mathrm{P}_{\mathrm{s}}=0,1 \mathrm{bar}$

$\mathrm{T}_{\mathrm{s}}=48,6{ }^{\circ} \mathrm{C}$

$\mathrm{F}_{\mathrm{s}}=40,35 \mathrm{t} / \mathrm{h}$

$\mathrm{F}_{\mathrm{s}}=0,24 \mathrm{t} / \mathrm{h}$

Dari data tersebut dapat dihitung: 
29 La Ode Musa, Abdul Rahman, Ikral Gapshel, Triska Sombokanan. Analisis Performansi Turbin dan Generator di PLTP Lahendong Unit 1 Tomohon

$$
\begin{aligned}
\mathrm{W}_{\mathrm{t}} & =\mathrm{h}_{1}-\mathrm{h}_{2} \\
& =2768,9 \mathrm{~kJ} / \mathrm{kg}-2257,5 \mathrm{~kJ} / \mathrm{kg} \\
& =511,3 \mathrm{~kJ} / \mathrm{kg}
\end{aligned}
$$

Berdasarkan sistem proteksi di PLTP Lahendong setting putaran sebagai berikut:

$\mathrm{N}_{\max }=3123 \mathrm{rpm}$

$\mathrm{N}_{\min }=2850 \mathrm{rpm}$

$\mathrm{N}=3000 \mathrm{rpm}$

Jadi toleransi putaran generator:

$$
\begin{aligned}
\operatorname{tg} & =\frac{\Delta N}{2 N} \times 100 \\
= & \frac{2^{2.3}}{2^{2.3}} \times 100 \\
= & \frac{2^{6}}{6} \times 100 \\
= & 4,5 \%
\end{aligned}
$$

\section{Analisa Performansi Turbin Dan Generator}

Data yang diambil untuk perhitungan performansi turbin dan generator adalah data dari control room pada tahun 2001 dan tahun 2015. Data operasional turbin dan kondensor pada bulan Desember 2001.

Tabel 1. Data penelitian pada tanggal 31 Desember 2001

\begin{tabular}{|l|l|l|l|l|l|}
\hline \multirow{2}{*}{ No } & \multirow{4}{*}{ Jam } & \multicolumn{3}{|l|}{ Turbin } & Kondensor \\
\cline { 3 - 6 } & & Flaw & Pressure & Temperature & Pressure \\
\hline & th & Bar & ${ }^{\circ} \mathrm{C}$ & Bar \\
\hline 1 & $0: 00$ & 154 & 8.3 & 180 & 0,1 \\
\hline 2 & $0: 30$ & 155 & 8.3 & 180 & 0,1 \\
\hline 3 & $1: 00$ & 155 & 8.3 & 179 & 0,1 \\
\hline 4 & $1: 30$ & 154 & 8.3 & 181 & 0,1 \\
\hline 5 & $2: 00$ & 154 & 8.4 & 182 & 0,1 \\
\hline 6 & $2: 30$ & 155 & 8.4 & 182 & 0,1 \\
\hline 7 & $3: 00$ & 154 & 8.4 & 182 & 0,1 \\
\hline 8 & $3: 30$ & 154 & 8.4 & 182 & 0,1 \\
\hline 9 & $4: 00$ & 154 & 8.4 & 182 & 0,1 \\
\hline 10 & $4: 30$ & 156 & 8.3 & 181 & 0,1 \\
\hline 11 & $5: 00$ & 155 & 8.3 & 181 & 0,1 \\
\hline 12 & $5: 30$ & 155 & 8.3 & 178 & 0,1 \\
\hline
\end{tabular}
berikut:

Berdasarkan Tabel 1, diambil data No.1 pada tanggal 31 Desember 2001 untuk dianalisa sebagai

$$
\begin{aligned}
& \mathrm{P}_{1}=8,3 \text { bar } \\
& \mathrm{T}_{1}=180{ }^{\circ} \mathrm{C} \\
& \mathrm{F}=154 \mathrm{t} / \mathrm{h}=42,78 \mathrm{~kg} / \mathrm{s} \\
& \mathrm{P}_{2}=0,1 \text { bar }
\end{aligned}
$$

Perhitungan untuk mencari h1 diambil dari Tabel Properties of Saturated Water (Liquid-Vapor), Pada $\mathrm{P}_{1}=8,3$ bar, dan $\mathrm{T}_{1}=180{ }^{\circ} \mathrm{C}$ dengan cara interpolasi maka didapatkan nilai $\mathrm{h} 1=2770,5 \mathrm{~kJ} / \mathrm{kg}$ dan cara interpolasi maka didapatkan nilai $\mathrm{s} 1=6,6507 \mathrm{~kJ} / \mathrm{kg} \circ \mathrm{K}$.

Pada saat tekanan 0,1 bar di dalam kondensor dari tabel uap diperoleh:

$$
\begin{aligned}
& \mathrm{h}_{\mathrm{f} 2}=191,83 \mathrm{~kJ} / \mathrm{kg} \\
& \mathrm{h}_{\mathrm{fg} 2}=2392,8 \mathrm{~kJ} / \mathrm{kg} \\
& \mathrm{h}_{\mathrm{g} 2}=2584,3 \mathrm{~kJ} / \mathrm{kg} \\
& \mathrm{S}_{\mathrm{f} 2}=0,6493 \mathrm{~kJ} / \mathrm{kg} \circ \mathrm{K}
\end{aligned}
$$




$$
\mathrm{S}_{\mathrm{g} 2}=8,1502 \mathrm{~kJ} / \mathrm{kg} \circ \mathrm{K}
$$

Dari data interpolasi diatas didapat kualitas uap keluaran kondensor sebagai berikut:

$$
\begin{array}{ll}
= & 6,6 \quad-0,6 \\
\hline 8,1 & -0,6 \\
=0,80 &
\end{array}
$$

Perhitungan entalpi keluaran turbin $\left(\mathrm{h}_{2}\right)$

$$
\begin{aligned}
\mathrm{h}_{2} & =\mathrm{hf}_{2}+\mathrm{X} \mathrm{hfg} \mathrm{hg}_{2} \\
& =191,83 \mathrm{~kJ} / \mathrm{kg}+0,80.2392,8 \mathrm{~kJ} / \mathrm{kg} \\
& =2106,07 \mathrm{~kJ} / \mathrm{kg}
\end{aligned}
$$

Jadi kualitas uap yang keluar dari kondensor adalah $80 \%$ Uap dan $20 \%$ air.

Dengan hasil diatas maka memperoleh nilai dari kerja turbin per kg sebagai berikut:

$$
\begin{aligned}
\mathrm{w}_{\mathrm{t}} & =\mathrm{h}_{1}-\mathrm{h}_{2} \\
& =(2770,5 \mathrm{~kJ} / \mathrm{kg}-2106,07 \mathrm{~kJ} / \mathrm{kg}) \\
& =664,43 \mathrm{~kJ} / \mathrm{kg} \\
\eta & =\frac{w t}{w t s} \times 100 \% \\
& =\frac{511,3}{664,43} \times 100 \% \\
& =77 \%
\end{aligned}
$$

$$
X_{2}=\frac{S_{1}-S_{2}}{S_{2}-S_{2}}
$$

Jadi daya turbin yang dihasilkan :

$$
\begin{aligned}
\mathrm{P}_{\mathrm{t}} & =\dot{\mathrm{m}} \times \eta \times \mathrm{w}_{\mathrm{t}} \\
& =42,78 \mathrm{~kg} / \mathrm{s} \times 0,77 \times 664,43 \mathrm{~kJ} / \mathrm{kg} \\
& =21,886 \mathrm{MW}
\end{aligned}
$$

Dengan nilai efisiensi generator yang digunakan adalah $91 \%$ (nilai $91 \%$ berdasarkan name plat $\mathrm{P}_{\mathrm{g}}=$ $20 \mathrm{MW}$ dan $\mathrm{P}_{\mathrm{t}}=22 \mathrm{MW}$ ) maka nilai daya listrik yang dihasilkan sebesar

$$
\begin{aligned}
\mathrm{P}_{\mathrm{g}} & =\mathrm{P}_{\mathrm{t}} \times \eta_{\mathrm{g}} \\
& =21.886 \times 0,91 \\
& =19,91 \mathrm{MW}
\end{aligned}
$$

Toleransi generator

$$
\begin{aligned}
\mathrm{t}_{\mathrm{g}} & =\frac{\Delta N}{2 N} \times 100 \\
& =\frac{3008-3000}{2.3000} \times 100 \\
& =\frac{\mathrm{g}}{6000} \times 100 \\
& =0,13 \%
\end{aligned}
$$


31 La Ode Musa, Abdul Rahman, Ikral Gapshel, Triska Sombokanan. Analisis Performansi Turbin dan Generator di PLTP Lahendong Unit 1 Tomohon

Tabel 2. Data penelitian tanggal 25 Oktober 2015

\begin{tabular}{|c|c|c|c|c|c|}
\hline \multirow{3}{*}{ Ne } & \multirow{3}{*}{ Jam } & \multicolumn{3}{|c|}{ Turbin } & \multirow{2}{*}{$\frac{\text { Kondensor }}{\text { Pressure }}$} \\
\hline & & Flow & Pressure & Temperature: & \\
\hline & & th & Bar & ${ }^{\circ} \mathrm{C}$ & Bar \\
\hline 1 & $0: 00$ & 129.15 & 7.96 & 170.91 & 0,12 \\
\hline 2 & $0: 30$ & 127.15 & 8.11 & 171.57 & 0,12 \\
\hline 3 & $1: 00$ & 130.41 & 7.96 & 170.81 & 0,12 \\
\hline 4 & $1: 30$ & 129.15 & 7.85 & 170.66 & 0,12 \\
\hline 5 & $2: 00$ & 129.15 & 7.85 & 170.58 & 0,12 \\
\hline 6 & $2: 30$ & 129.15 & 7.86 & 170.79 & 0,12 \\
\hline 7 & $3: 00$ & 129.15 & 7.87 & 170.83 & 0,12 \\
\hline 8 & $3: 30$ & 129.15 & 7.81 & 170.59 & 0,12 \\
\hline 9 & $4: 00$ & 129.15 & 7.82 & 170.57 & 0,12 \\
\hline 10 & $4: 30$ & 129.15 & 7.93 & 170.99 & 0,12 \\
\hline 11 & $5: 00$ & 129.15 & 7.94 & 171.02 & 0,12 \\
\hline 12 & $5: 30$ & 129.15 & 7.83 & 170.76 & 0,12 \\
\hline
\end{tabular}
berikut:

Berdasarkan Tabel 2 diambil data No. 1 pada tanggal 25 Oktober 2015 untuk dianalisa sebagai

$\mathrm{P}_{1}=7,96$ bar

$\mathrm{T}_{1}=170,91{ }^{\circ} \mathrm{C}$

$\mathrm{F}=129,15 \mathrm{t} / \mathrm{h}=35,87 \mathrm{~kg} / \mathrm{s}$

$\mathrm{P}_{2}=0,12$ bar

Perhitungan untuk mencari $\mathrm{h}_{1}$ diambil dari Table Properties of Saturated Water (Liquid-Vapor). Pada $\mathrm{P} 1=7,96$ bar, dan $\mathrm{T} 1=170,91{ }^{\circ} \mathrm{C}$ dengan cara interpolasi maka didapatkan nilai $\mathrm{h} 1=2768,9$ $\mathrm{kJ} / \mathrm{kg}$ dan $\mathrm{s} 1=6.6646 \mathrm{~kJ} / \mathrm{kg} \circ \mathrm{K}$.

Pada saat tekanan 0,12 bar di dalam kondensor dari tabel uap diperoleh:

$$
\begin{aligned}
& \mathrm{h}_{\mathrm{f} 2}=203,74 \mathrm{~kJ} / \mathrm{kg} \\
& \mathrm{h}_{\mathrm{fg} 2}=2385,9 \mathrm{~kJ} / \mathrm{kg} \\
& \mathrm{h}_{\mathrm{g} 2}=2589,7 \mathrm{~kJ} / \mathrm{kg} \\
& \mathrm{S}_{\mathrm{f} 2}=0,6858 \mathrm{~kJ} / \mathrm{kg} \circ \mathrm{K} \\
& \mathrm{S}_{\mathrm{g} 2}=8,1019 \mathrm{~kJ} / \mathrm{kg} \circ \mathrm{K}
\end{aligned}
$$

Dari data interpolasi diatas didapat kualitas uap keluaran kondensor sebagai berikut:

$$
\begin{aligned}
& X_{2}=\frac{S_{1}-S_{2}}{S_{2}-S_{2}} \\
& =\frac{6,6-0,6}{8,1-0,6} \\
& =0,806
\end{aligned}
$$

Dari hasil diatas diperoleh nilai $\mathrm{h}_{2}$

$$
\begin{aligned}
\mathrm{h}_{2} & =\mathrm{hf}_{2}+\mathrm{X} \mathrm{hfg} \\
& =203,74 \mathrm{~kJ} / \mathrm{kg}+0,806.2385,9 \mathrm{~kJ} / \mathrm{kg} \\
& =2126,7 \mathrm{~kJ} / \mathrm{kg}
\end{aligned}
$$

Jadi kualitas uap yang keluar dari kondensor adalah 80,6\% uap dan 19,4\% air.

Dengan hasil diatas maka memperoleh nilai dari kerja turbin per kg sebagai berikut $\mathrm{w}_{\mathrm{t}}=\mathrm{h}_{1}-\mathrm{h}_{2}$ 


$$
\begin{aligned}
& =2773,9 \mathrm{~kJ} / \mathrm{kg}-2126,7 \mathrm{~kJ} / \mathrm{kg}) \\
& =647,2 \mathrm{~kJ} / \mathrm{kg} \\
\eta & =\frac{w t}{w t s} \times 100 \% \\
& =\frac{511,3}{647,2} \times 100 \% \\
& =79 \%
\end{aligned}
$$

Jadi daya turbin yang dihasilkan :

$$
\begin{aligned}
\mathrm{P}_{\mathrm{t}} & =\dot{\mathrm{m}} \mathrm{x} \cap \mathrm{x} \mathrm{w}_{\mathrm{t}} \\
& =35,87 \mathrm{~kg} / \mathrm{s} \times 0,79 \times 647,2 \mathrm{~kJ} / \mathrm{kg} \\
& =18,33 \mathrm{MW}
\end{aligned}
$$

Dengan nilai efisiensi generator yang digunakan adalah $91 \%$ (nilai $91 \%$ berdasarkan name plat $\mathrm{P}_{\mathrm{g}}=$ $20 \mathrm{MW}$ dan $\mathrm{P}_{\mathrm{t}}=22 \mathrm{MW}$ ) maka nilai daya listrik yang dihasilkan sebesar

$$
\begin{aligned}
\mathrm{P}_{\mathrm{g}} & =\mathrm{P}_{\mathrm{t}} \times \eta_{\mathrm{g}} \\
& =18,33 \times 0,91 \\
& =16,689 \mathrm{MW}
\end{aligned}
$$

Toleransi generator

$$
\begin{aligned}
\mathrm{t}_{\mathrm{g}} & =\frac{\Delta N}{2 N} \times 100 \\
& =\frac{3029-2974}{2.3000} \times 100 \\
& =\frac{55}{6000} \times 100 \\
& =0,92 \%
\end{aligned}
$$

\section{B. Pembahasan}

Berdasarkan Gambar 2, pada tahun 2001 dan 2015 kualitas uap yang paling besar pada bulan oktober 2015. Hal ini juga terlihat pada Gambar 3, nilai entropi terbesar pada bulan oktober 2015, hal ini terjadi karena besar kecilnya kualitas uap. Kualitas uap dipengaruhi nilai entropi, sedangkan nilai entropi sendiri dipengaruhi perubahan tekanan dan temperatur.

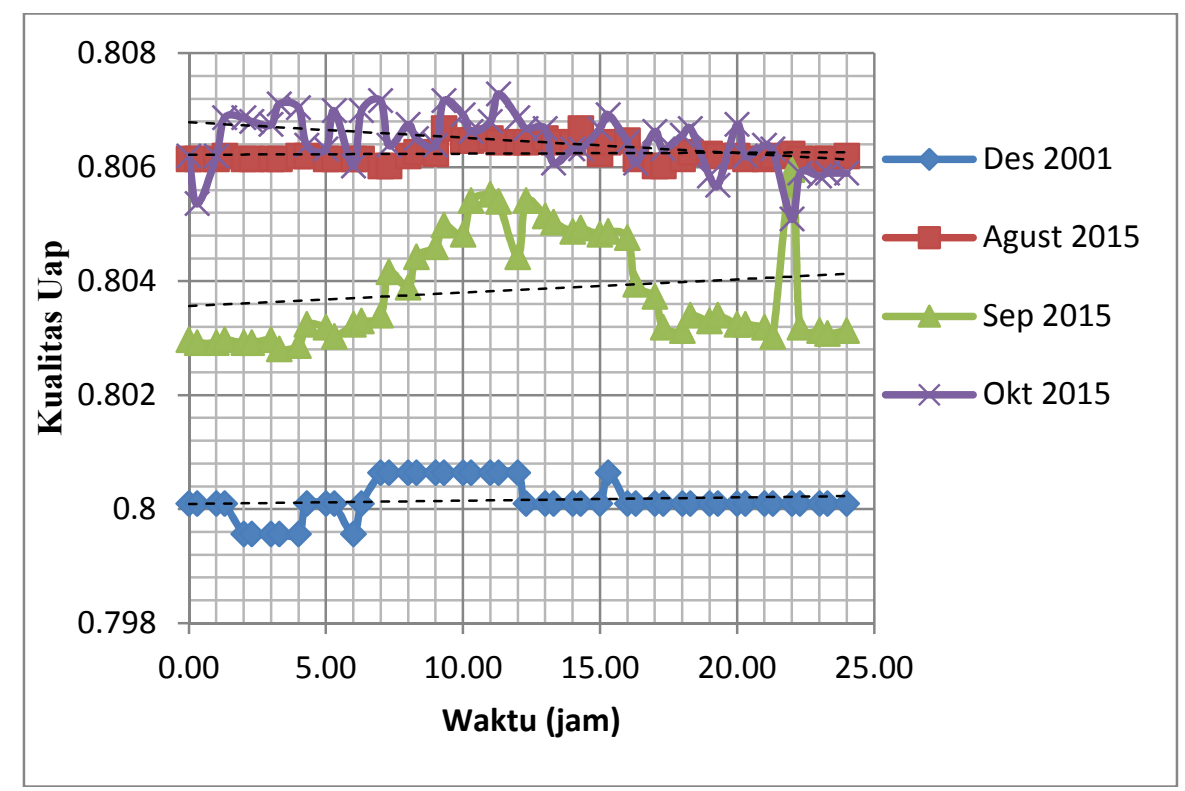

Gambar 2. Grafik nilai flow uap (ton/h) berdasarkan waktu (jam) operasi 
33 La Ode Musa, Abdul Rahman, Ikral Gapshel, Triska Sombokanan. Analisis Performansi Turbin dan Generator di PLTP Lahendong Unit 1 Tomohon

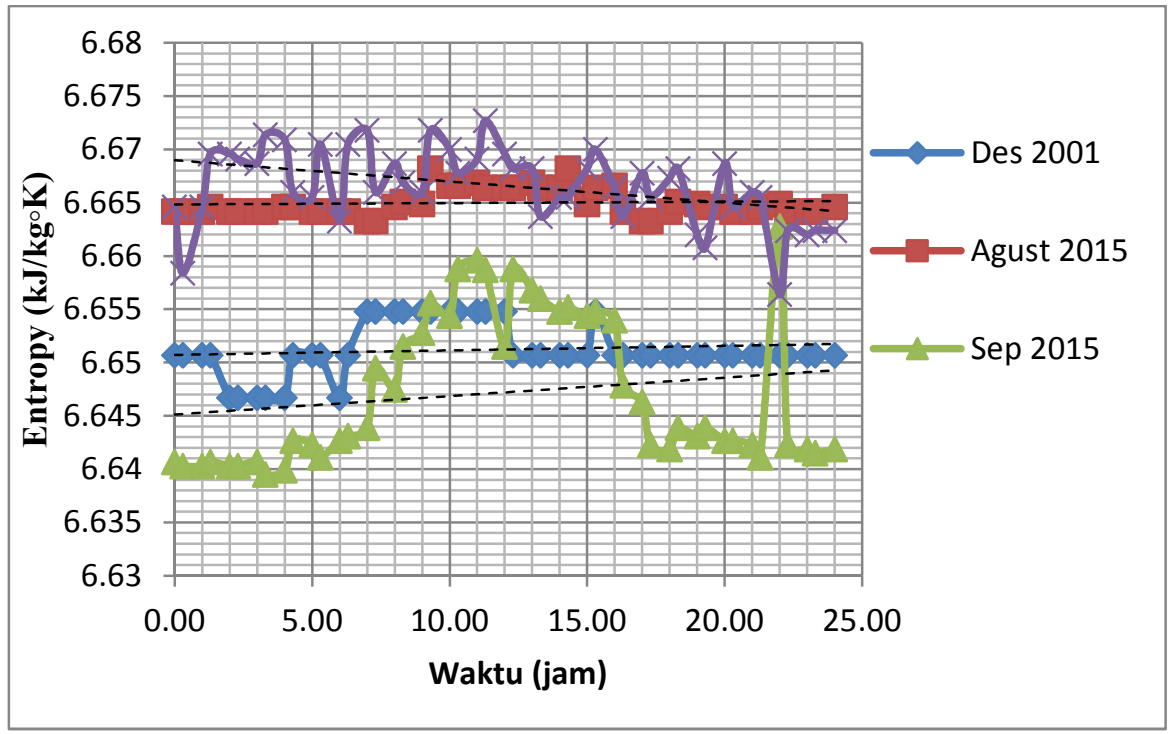

Gambar 3. Grafik nilai flow uap (ton/h) berdasarkan waktu (jam) operasi

Berdasarkan Gambar 4, pada tahun 2001 kinerja turbin $665 \mathrm{~kJ} / \mathrm{kg}$ dan tahun 2015 kinerja turbin mengalami penurunan sekitar $635 \mathrm{~kJ} / \mathrm{kg}$. Dalam kondisi ideal kinerja turbin adalah $511,3 \mathrm{~kJ} / \mathrm{kg}$.

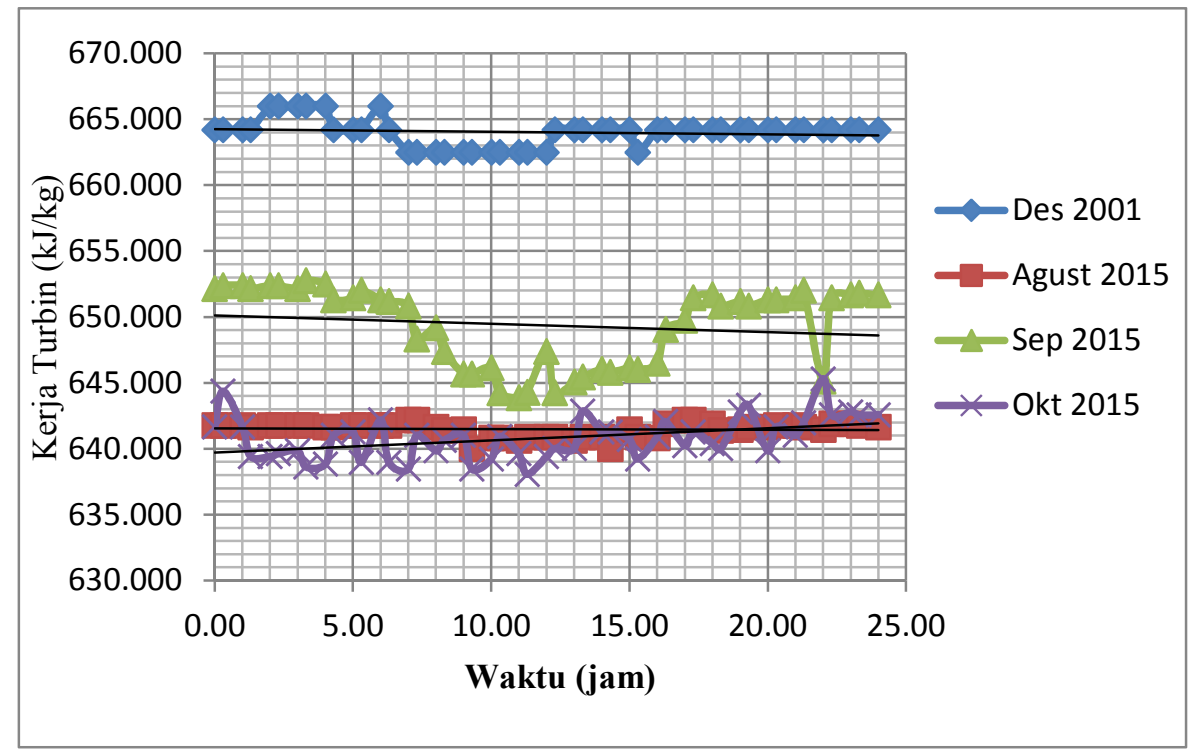

Gambar 4. Grafik nilai kerja turbin spesifik (kJ/kg) berdasarkan waktu (jam) operasi

sedangkan pada Gambar 5 didapat nilai efisiensi turbin mengalami peningkatan, namun hal ini belum menjamin turbin menghasilkan keluaran daya yang optimal. 


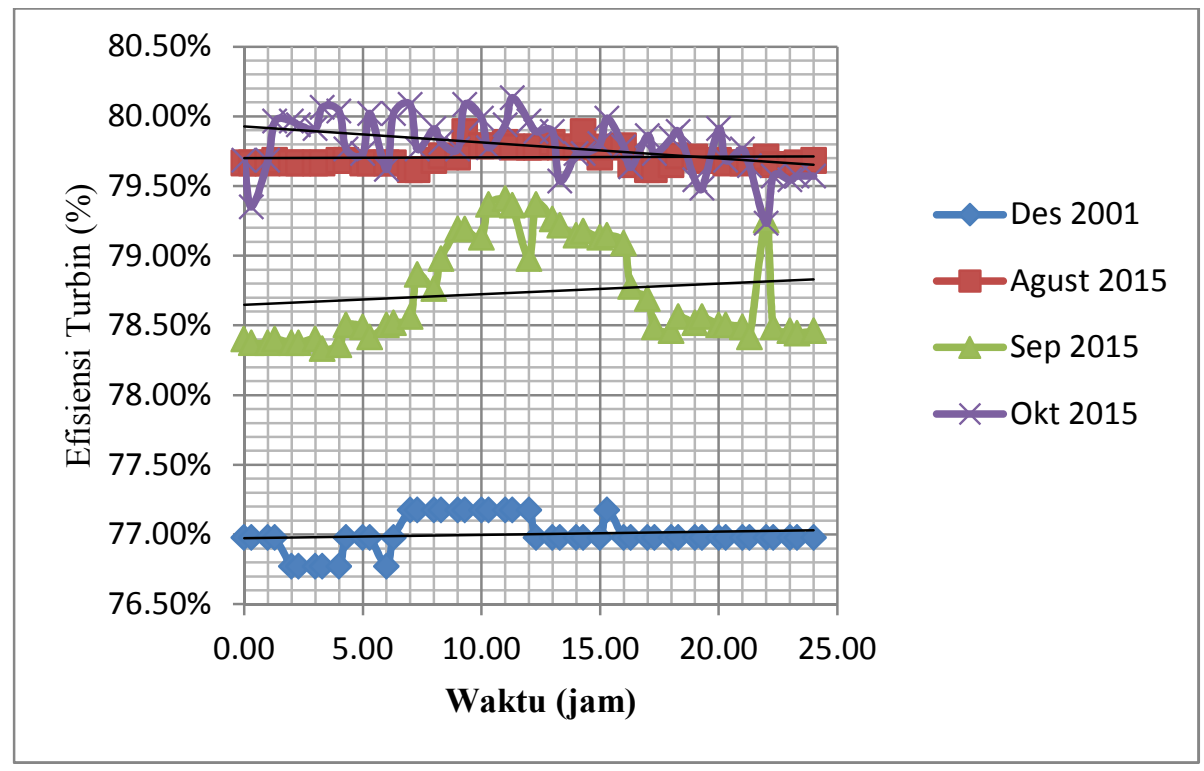

Gambar 5. Grafik nilai efisiensi (\%) berdasarkan waktu (jam) operasi

Pada gambar 25 terlihat turbin mengalami peningkatan efisiensi turbin akan tetapi daya yang dihasilkan mengalami penurunan pada tahun 2015 sekitar 19 MW dari 22 MW yang dihasilkan pada tahun 2001.

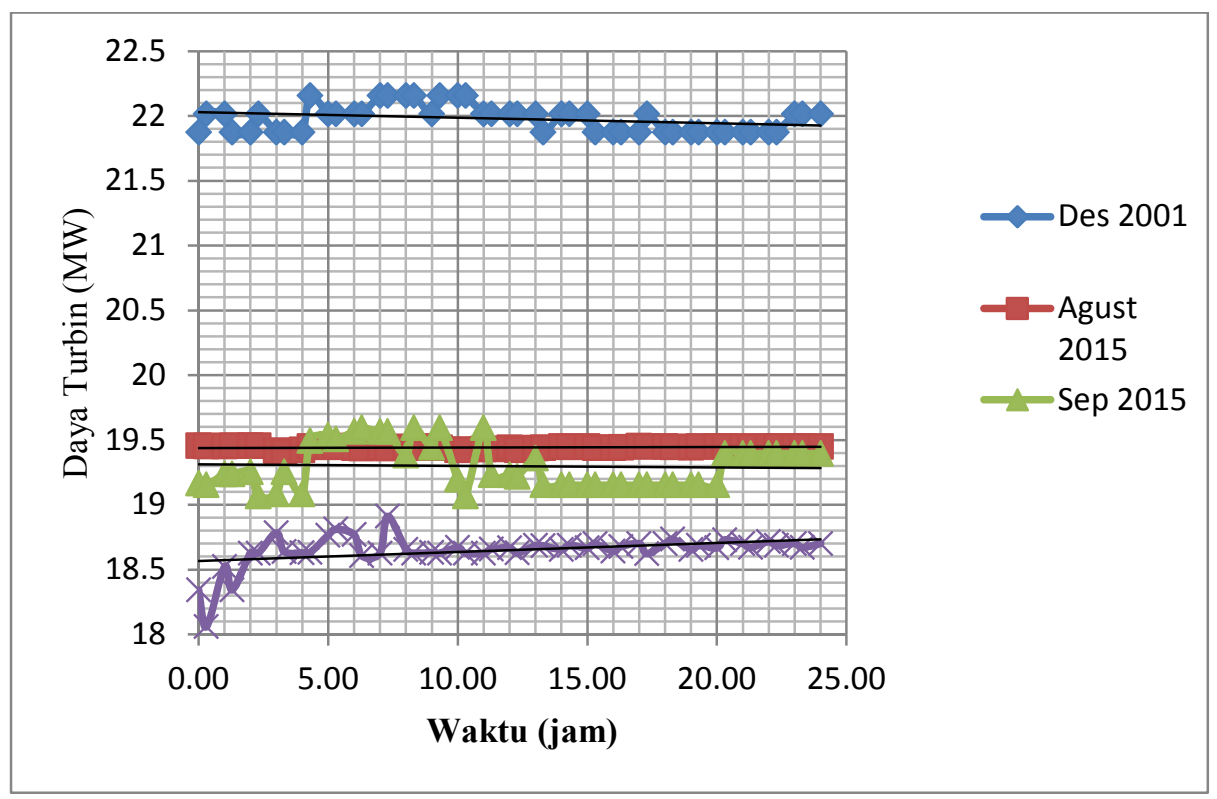

Gambar 6. Grafik nilai daya turbin (MW) berdasarkan waktu (jam) operasi

Penurunan ini terjadi karena adanya korosi dalam pipa aliran uap, nilai laju aliran massa mengalami penurunan sekitar 135 ton/h dari 154 ton/h pada tahun 200, fenomenaini dapat di lihat pada Gambar 7 . 
35 La Ode Musa, Abdul Rahman, Ikral Gapshel, Triska Sombokanan. Analisis Performansi Turbin dan Generator di PLTP Lahendong Unit 1 Tomohon

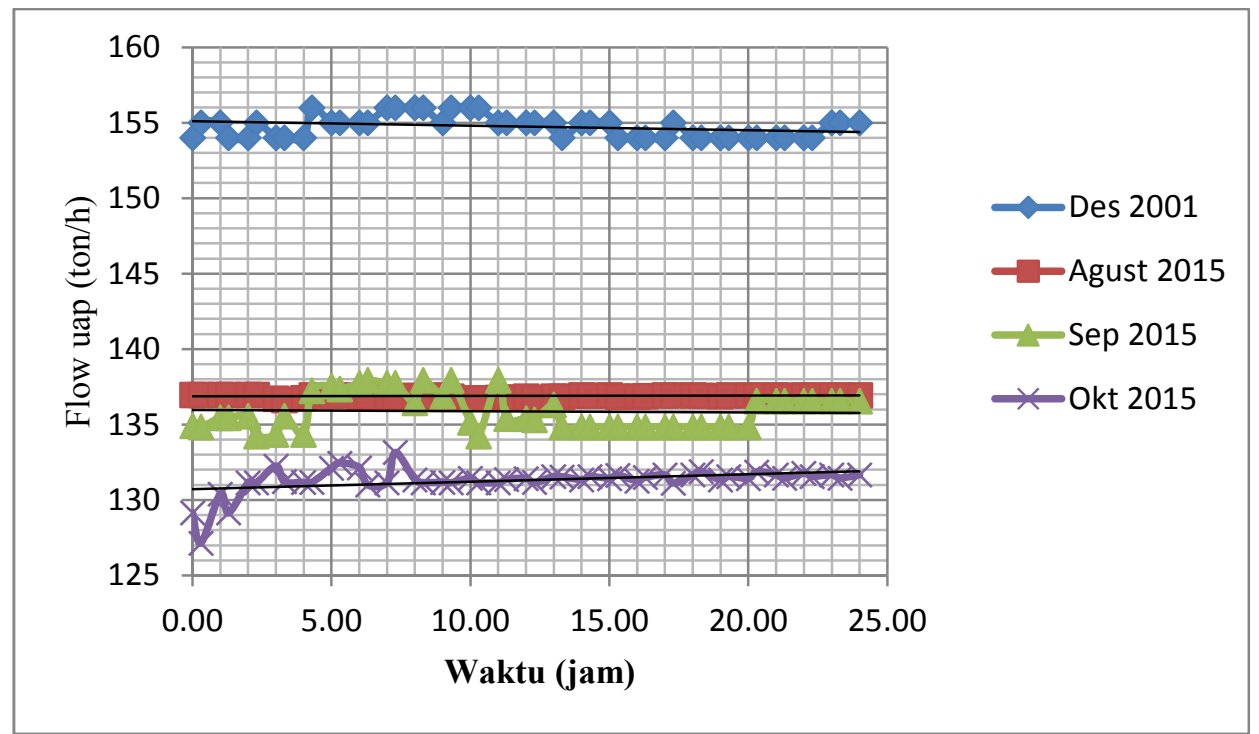

Gambar 7. Grafik nilai flow uap (ton/h) berdasarkan waktu (jam) operasi

Berdasarkan Gambar 8 dan Gambar 9, pada tahun 2001 nilai putaran generator $3000 \mathrm{rpm}$ dan tahun 2015 nilai putaran generator mengalami ketidakstabilan sehingga toleransi generator mengalami peningkatan sekitar $0,92 \%$ dari $0,13 \%$ pada tahun 2001, namun hal ini masih memungkinkan generator untuk menghasilkan daya listrik karena toleransi generator yang di izinkan oleh pihak PT. PLN sebesar 4,5\%.

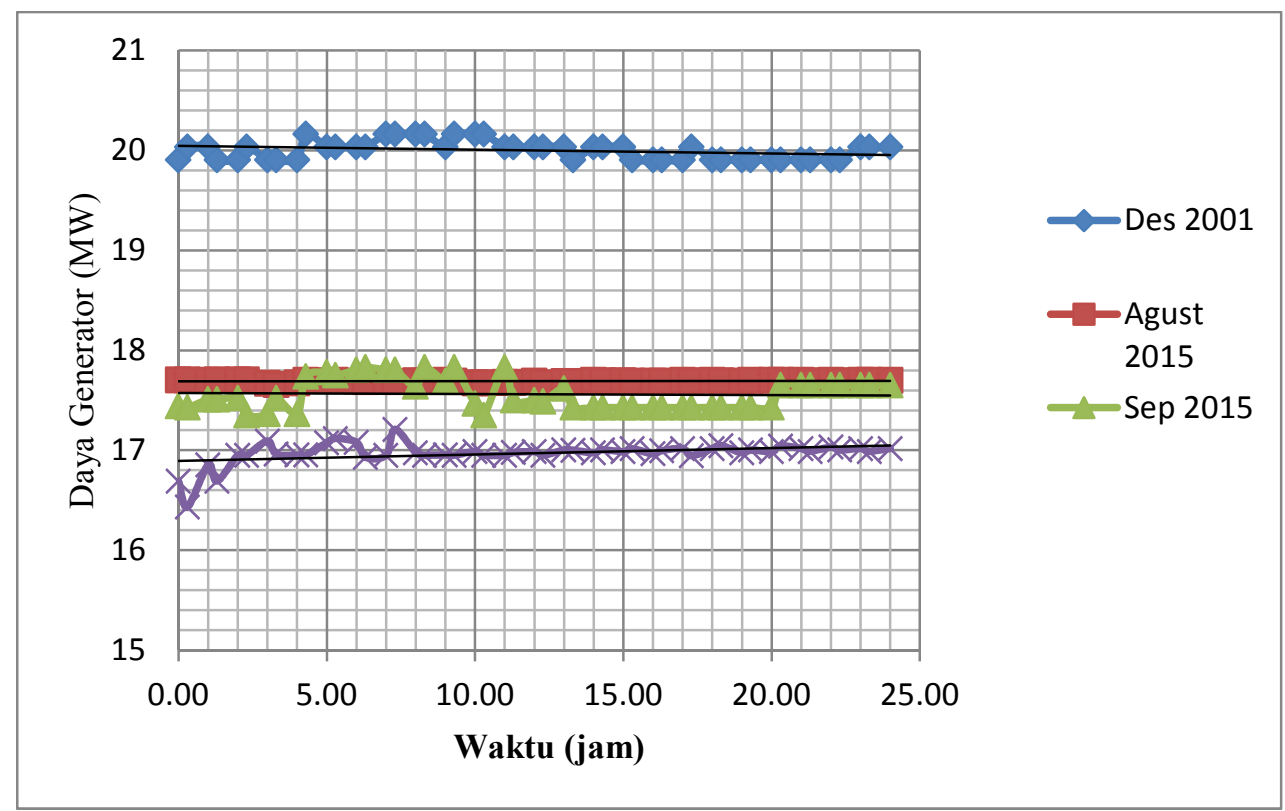

Gambar 8. Grafik nilai daya generator (MW) berdasarkan waktu (jam) operasi 


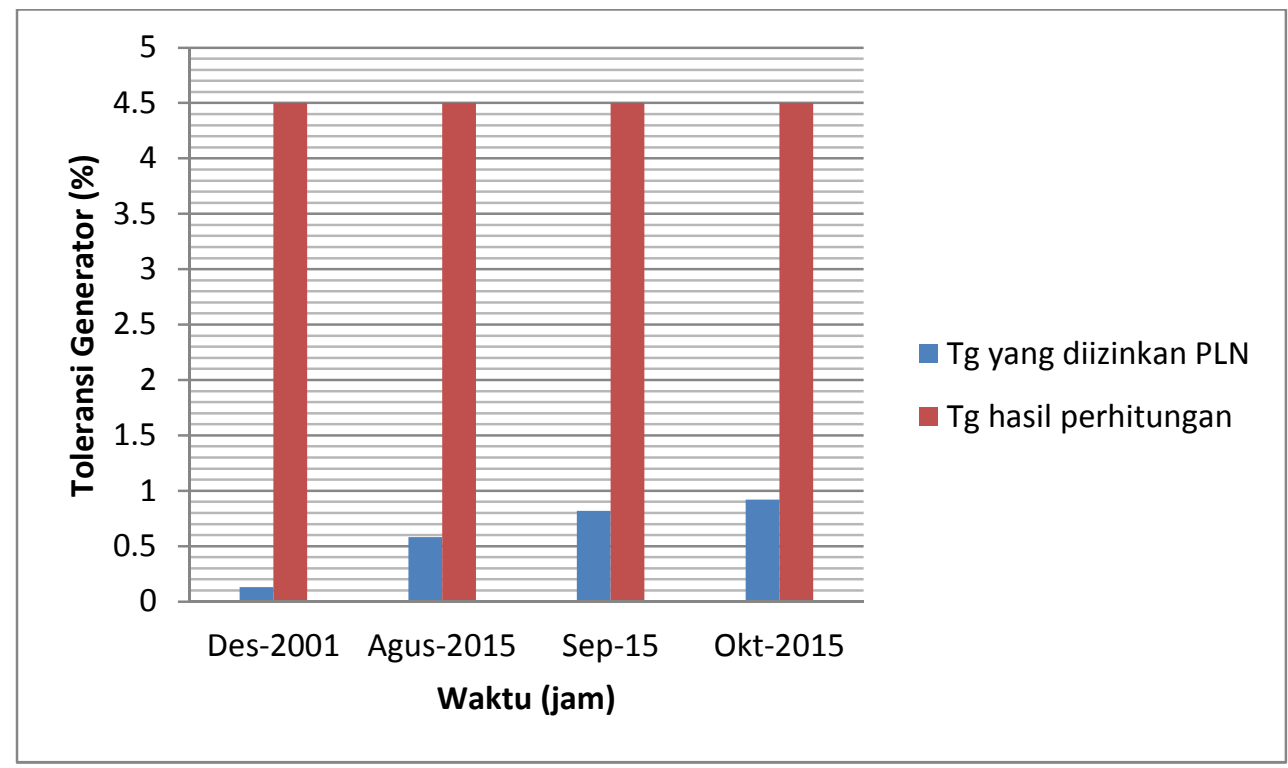

Gambar 9. Grafik perbandingan nilai toleransi generator yang diizinkan dengan hasil perhitungan

\section{KESIMPULAN}

1. Kualitas uap pada PLTP Lahendong dari awal operasi tahun 2001 dengan rata-rata 0,8002 sampai tahun 2015 dengan rata-rata 0,8065 tidak stabil, namun tetap dalam kondisi yang baik.

2. Performansi turbin dan generator masing-masing pada 31 Desember 2001 adalah rata-rata $664.012 \mathrm{~kJ} / \mathrm{kg}, 20 \mathrm{MW}$, pada 14 Agustus 2015 adalah rata-rata 641,481 kJ/kg, 17,69 MW, pada 1 September 2015 adalah rata-rata 649,372 kJ/kg, 17,56 MW, dan pada 25 Oktober 2015 adalah rata-rata $640,799 \mathrm{~kJ} / \mathrm{kg}, 16,97 \mathrm{MW}$. Performansi terus mengalami penurunan dari tahun ke tahun tapi masih dalam kondisi yang baik

3. Perbandingan performansi turbin di PLTP Lahendong yaitu pada kondisi awal tahun 2001 dengan rata-rata $664,021 \mathrm{~kJ} / \mathrm{kg}$ dan pada kondisi saat ini tahun 2015 dengan rata-rata $640,799 \mathrm{~kJ} / \mathrm{kg}$. Dengan toleransi putaran generator tertinggi $0,9 \%$ masih dalam standar PLN

\section{DAFTAR PUSTAKA}

[1] I. Katherin,dkk,”Optimasi Daya Listrik pada PT Pertamina Geothermal Energy Area Kamojang, Jawa Barat". Jurnal Teknik Pomits Vol. 1, No. 1, 2012.

[2] PT. PLN (Persero) Lahendong I Geothermal Project, “ Pengetahuan Dasar Pembangkit” Manado: PLTP Lahendong, 2000.

[3] PT. PLN (Persero) Lahendong I Geothermal Project, "Manual Cooling Water System”. Manado: PLTP Lahendong, 2000.

[4] M. M. El-Wakil, Instalasi Pembangkit Daya. jilid 1. Jakarta: Erlangga, 1992.

[5] Y. S. Nugroho,'Termodinamika Teknik jilid 1". Jakarta: Erlangga,2006. 